\title{
A ORIGEM DOS CLORETOS NAS ÁGUAS SUBTERRÂNEAS NA CHAPADA DO APODI - CEARÁ
}

\author{
Maria Aparecida Belém Fernandes ${ }^{1}$, Maria Marlúcia Freitas Santiago, Diolande Ferreira Gomes ${ }^{1}$, \\ Josué Mendes Filho ${ }^{1}$, Horst Frischkorn² e José Ossian Gadelha de Lima ${ }^{1}$
}

Recebido em 20/05/2004, aceito em 02/09/2004

\begin{abstract}
RESUMO A salinidade das águas subterrâneas armazenadas nos calcários da Formação Jandaíra, que aflora na Chapada do Apodi, foi estudada através das concentrações de cloretos, sódio e potássio, da condutividade elétrica. Em adição, medidas de pH e de oxigênio-18 foram feitas. Em parte da área estudada, está implantada a Fazenda Frutacor que desenvolve plantio de bananas para exportação utilizando água subterrânea captada por poços com profundidade média de $45 \mathrm{~m}$. Nesta atividade, $\mathrm{KCl}$ é utilizado intensivamente como fertilizante, durante todo o ano. O monitoramento durante 13 meses mostrou aumento na concentração de $\mathrm{K}^{+}$e que também, aumentaram a condutividade elétrica e a concentração de cloretos depois de ter baixado durante a época de chuvas. Medidas de oxigênio-18 indicaram processo de evaporação. A comparação da condutividade elétrica em área irrigada e em área não irrigada sugere o efeito antrópico do uso do fertilizante sobre este parâmetro.
\end{abstract}

Palavras-chave: salinização, Chapada do Apodi, água subterrânea.

ABSTRACT The salinity of groundwater from the calcareous Jandaíra formation, that outcrops on the Apodi plateau, was studied through the concentrations of $\mathrm{Cl}^{-}, \mathrm{Na}^{+}, \mathrm{K}^{+}$, and electric conductivity. In addition, measurements of $\mathrm{pH}$ and oxygen-18 were made. The Frutacor Farm, whose main activity is banana plantation for export, is located in part of the studied area and exploits groundwater for irrigation purpose through wells with $45 \mathrm{~m}$ depth in average. $\mathrm{KCl}$ is intensively used throughout the whole year to increase soil fertility. During a monitoring period of 13 months, $\mathrm{K}^{+}$showed a practically continuous increase. Electric conductivity and $\mathrm{Cl}^{-}$content showed decreasing values during the rainfall period. Oxygen-18 values indicate water affected by evaporation. Electric conductivity differences in measurements carried out in water samples collected from wells placed within and outside the irrigation area suggest anthropogenic influence caused by the use of fertilizers.

Keywords: salinization, Apodi Plateau, groundwater

\section{INTRODUÇÃO}

A Chapada do Apodi, localizada na divisa entre os estados do Ceará e do Rio Grande do Norte (Figura 1), a aproximadamente $240 \mathrm{~km}$ de Fortaleza, tem uma importante reserva de água subterrânea armazenada nos calcários clásticos e dolomíticos da formação Jandaíra.

Nesta área, a predominância de calcários e de arenitos desta Formação não favorece a presença de rios e riachos; portanto, recursos hídricos superficiais são escassos, o que leva à explotação dos recursos hídricos subterrâneos para utilização na irrigação de áreas agrícolas e consumo de pequenas comunidades. No entanto, a explotação de água subterrânea na Chapada é restrita a pequenas áreas, pois a profundidade do nível estático dos poços tem em média $24 \mathrm{~m}$, tornando sua utilização pouco viável economicamente.

Como os solos da chapada representam uma das mais importantes manchas sedimentares e uma das maiores áreas cultiváveis do Estado do Ceará, instalou-se aí o Projeto de Irrigação da Chapada do Apodi, constituído por empresas de fruticultura tropical. No setor leste da Chapada, próximo à encosta, foi instalado um sistema de recalque para elevar água do rio Jaguaribe para o sistema de canais do projeto, superando um desnível de aproximadamente $100 \mathrm{~m}$.

Em pequenas áreas localizadas fora do perímetro do projeto irriga-se com água subterrânea do aqüífero Jandaíra; porém, a salinidade, expressa pela condutividade elétrica, acima de $1500 \mu \mathrm{S} / \mathrm{cm}$ e $\mathrm{pH}$ acima de 6,0 a tornam pouco propícia para isso.

Neste trabalho, as concentrações salinas das águas subterrâneas foram acompanhadas através de análises de amostras coletadas de um conjunto de poços que fornecem água à Fazenda Frutacor, onde se produz banana para exportação, utilizando o fertilizante $\mathrm{KCl}$ duas vezes por semana através de gotejamento durante todo o ano. A irrigação com o sistema de pivot é feita como rotina diária no período seco e em dias sem chuvas no período chuvoso.

Os objetivos deste trabalho foram analisar a salinidade da água subterrânea na Chapada do Apodi, armazenada na Formação Jandaíra, e identificar o efeito do uso de $\mathrm{KCl}$ na adubação das áreas de plantio comparando as concentrações salinas dentro e fora da área irrigada.

\footnotetext{
${ }^{1}$ Departamento de Física da Universidade Federal do Ceará (maria@fisica.ufc.br), (marlucia@fisica.ufc.br), (josue@física.ufc.br)e (ossian@fisica.ufc.br).

${ }^{2}$ Departamento de Engenharia Hidráulica e Ambiental da Universidade Federal do Ceará (cariri@ufc.br).
} 


\section{ÁREA DE ESTUDO}

A Chapada do Apodi compreende um vasto planalto com desnível que chega a $100 \mathrm{~m}$ em relação ao vale do Jaguaribe (Figura 1). A área estudada, de 4,22 $\mathrm{km}^{2}$, pertence ao município de Quixeré, no Estado do Ceará, e nela está instalada a Fazenda Frutacor.

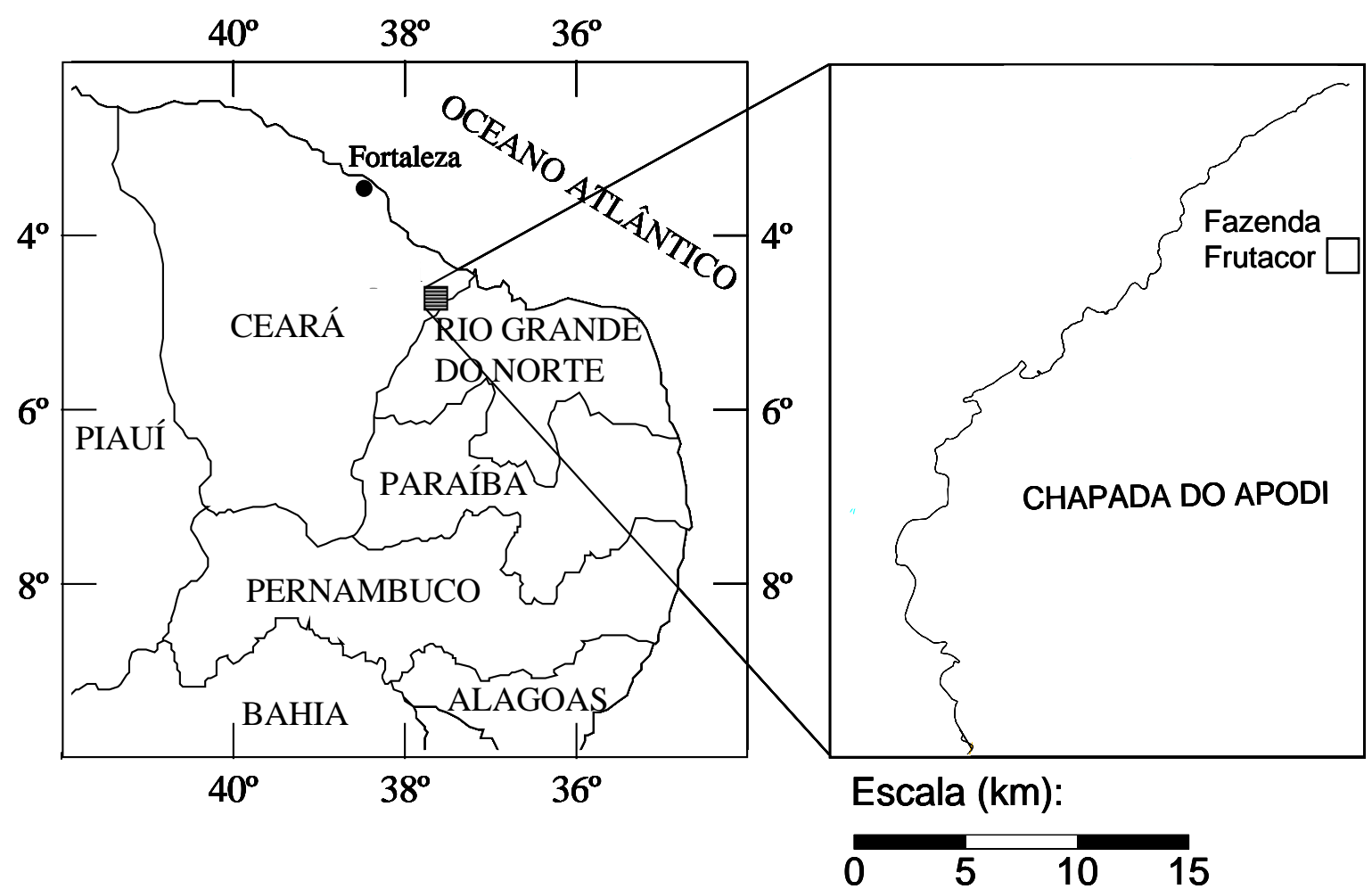

Figura 1 - Mapa com a localização da área de trabalho.

\section{Aspectos hidrogeológicos}

A Chapada do Apodi faz parte da Bacia Potiguar, onde as unidades estratigráficas estão representadas, predominantemente, pela formação calcária Jandaíra, com espessura média de 250 a $300 \mathrm{~m}$, no topo, e pelo arenito Açu, na base (FEITOSA, 1996).

A Formação Jandaíra caracteriza-se por carbonatos marinhos de águas rasas, e sua litologia dominante é constituída por calcários clásticos e dolomíticos compactos, duros, lajeados e fraturados. Estes sedimentos apresentam coloração creme e cinza. Em superfície, apresenta um relevo plano, pouco ondulado, solo argiloso, formando escarpas quando em contato com os arenitos mais antigos. Esta formação constitui um aqüífero livre, predominantemente cárstico, em que o armazenamento e a circulação de água ocorrem em fendas abertas pela dissolução, e é limitada na base por níveis argilosos da Formação Açu.

A Formação Açu caracteriza-se por sedimentos clásticos em camadas relativamente espessas, variando de areias finas a seixos. Esta formação tem comportamento de aqüífero confinado onde está sobreposto pelo Jandaíra e pelo seu nível superior mais argiloso, e de aqüífero livre, nas zonas de afloramento (zonas de recarga). Sua litologia é formada por arenitos brancos, cinza e avermelhados, com intercalações de folhelhos, siltitos e calcarenitos. Esta formação apresenta espessura média de $150 \mathrm{~m}$ na área de afloramento. Tem suave mergulho para o norte, quando aumenta gradativamente de espessura, chegando a atingir em média $500 \mathrm{~m}$.

O aqüífero Jandaíra apresenta água geralmente salobra, mas com composição química favorável a pequena irrigação. É um aqüífero livre ou confinado com vazões que chegam até $30 \mathrm{~m}^{3} / \mathrm{h}$, com média de $3 \mathrm{~m}^{3} / \mathrm{h}$.

\section{Clima}

O clima dominante da região é o semi-árido, caracterizado por uma estação chuvosa, nos meses de janeiro a maio, sendo janeiro e abril os mais chuvosos, e outra, seca, de julho a dezembro. A temperatura média anual é de 28,5 ${ }^{\circ} \mathrm{C}$, com mínima de $22{ }^{\circ} \mathrm{C}$ e máxima de $35^{\circ} \mathrm{C}$. A precipitação média anual é $772 \mathrm{~mm}$, registrandose uma distribuição interanual de chuvas muito irregular. A umidade relativa é de $62 \%$, como média anual. Os ventos sopram a uma velocidade média de $7,5 \mathrm{~m} / \mathrm{s}$ e a evapotranspiração atinge a 
média anual de $3.215 \mathrm{~mm}$. A região tem uma insolação de 3.030 horas/ano.

Dados de um posto de observação no município de Quixeré (FUNCEME), correspondentes aos anos 2000, 2001 e 2002 mostram uma pluviosidade média anual de 413mm, com mínima de 336 mm em 2001 e a máxima de 770 mm em 2000 (Figura 2).

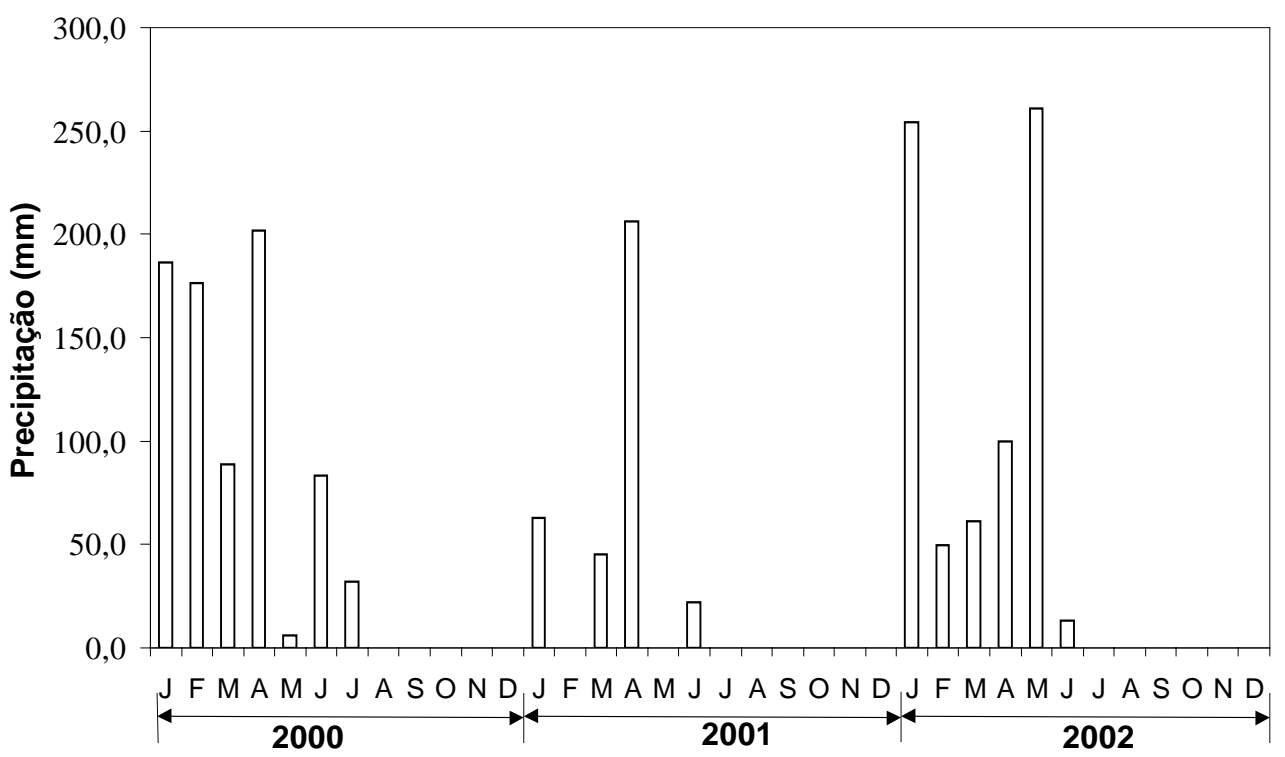

Figura 2 - Pluviosidade da Chapada do Apodi nos últimos três anos.

\section{MATERIAL E MÉTODOS}

Foram coletadas amostras para análise hidroquímica em seis poços em operação (Figura 3) com profundidade média de $45 \mathrm{~m}$. As coletas foram feitas durante um período de 13 meses.

Os parâmetros $\mathrm{pH}$, temperatura e condutividade elétrica foram medidos durante as coletas. As concentrações dos íons $\mathrm{K}^{+}$e $\mathrm{Cl}^{-}$foram determinadas no Laboratório de Hidroquímica do Grupo de Física Isotópica do Departamento de Física da Universidade Federal do Ceará (UFC), e a análise de oxigênio -18 foi realizada no CENA (Centro de Energia Nuclear na Agricultura - Piracicaba/SP).

Coletas de amostras para análise de oxigênio18 foram realizadas para identificar a influência do processo de evaporação sobre as águas. Os resultados das análises são expressos como o desvio da razão isotópica $\mathrm{R}={ }^{18} \mathrm{O} /{ }^{16} \mathrm{O}$ da amostra com relação à razão isotópica de um padrão, representado em valores de delta por mil $\left(\delta^{0} /{ }_{00}\right)$. O padrão utilizado é o VSMOW (Vienna Standard Mean Ocean Water) que corresponde, aproximadamente, à água média do oceano (CRAIG, 1961). Os valores de $\delta \%$ são obtidos através da expressão:

$$
\delta\left({ }^{0} /{ }_{00}\right)=\frac{R_{\text {amostra }}-R_{\text {padrão }}}{R_{\text {padrão }}} \times 10^{3}
$$

O erro $2 \sigma$ nas medidas de $\delta^{18} \mathrm{O}$ é de $\pm 0,15 \%$. Os métodos utilizados nas análises hidroquímica são os métodos padrões internacionais descritos em APHA (1992). 


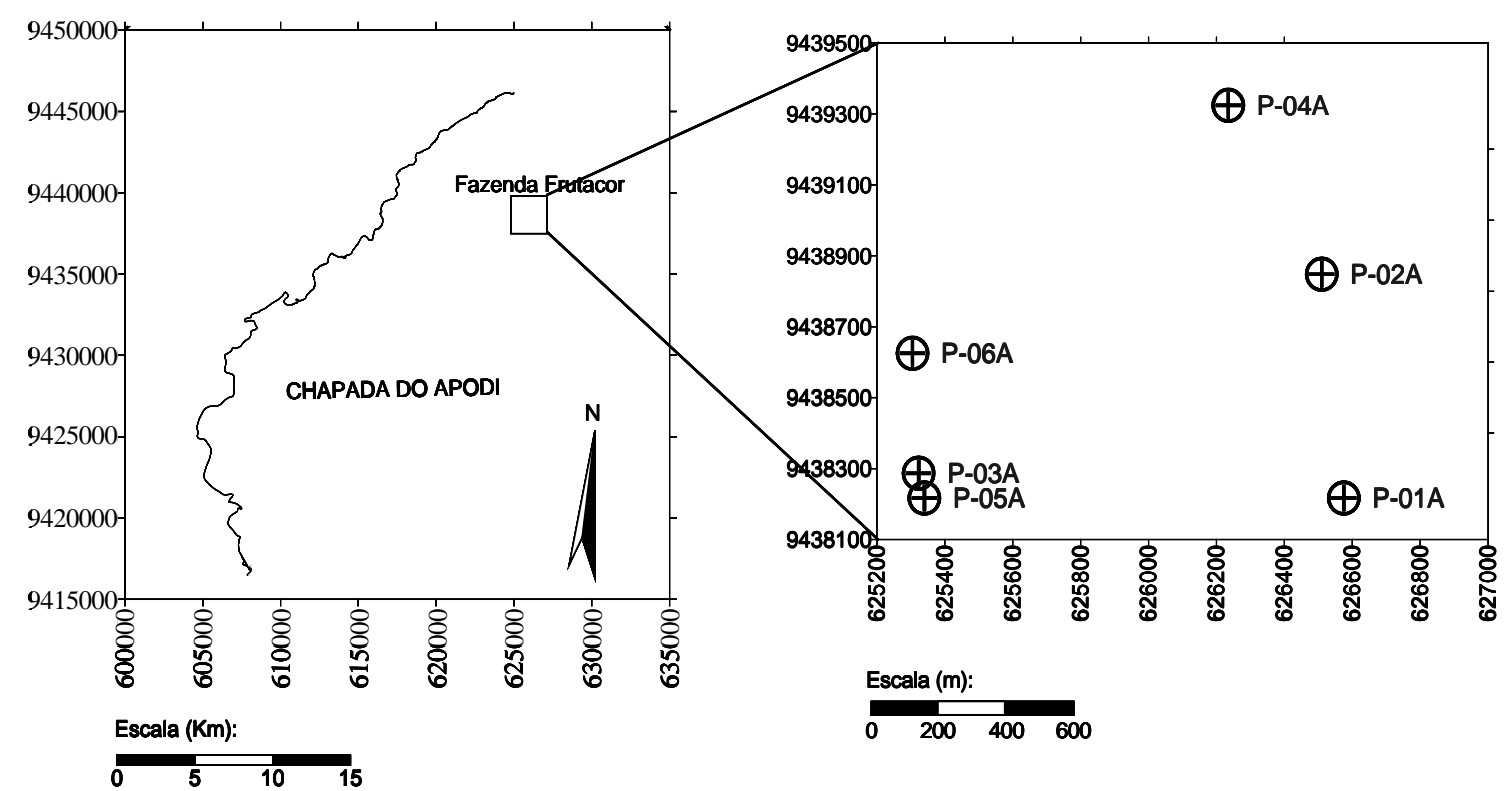

Figura 3 - Localização dos poços amostrados.

\section{RESULTADOS E DISCUSSÃO Hidroquímica}

Como o fertilizante cloreto de potássio é utilizado em grande quantidade na plantação de bananas, foram monitoradas as concentrações dos íons $\mathrm{Cl}^{-}$e $\mathrm{K}^{+}$, juntamente com a condutividade elétrica e $\mathrm{pH}$, em 6 poços da Fazenda Frutacor (Tabela 1). $\mathrm{O} \mathrm{Na}^{+}$também foi monitorado porque nas águas naturais $\mathrm{Cl}^{-}$está predominantemente associado a ele.

Tabela 1 - pH, Condutividade elétrica (CE) e concentrações de cloreto e potássio.

\begin{tabular}{|c|c|c|c|c|c|c|c|}
\hline \multirow{2}{*}{ Parâmetro } & \multirow{2}{*}{ Mês } & \multicolumn{6}{|c|}{ POÇOS } \\
\hline & & $\mathrm{P}-01 \mathrm{~A}$ & $\mathrm{P}-02 \mathrm{~A}$ & $\mathrm{P}-03 \mathrm{~A}$ & $\mathrm{P}-04 \mathrm{~A}$ & $P-05 A$ & $P-06 A$ \\
\hline \multirow{7}{*}{$\mathrm{pH}$} & ago/01 & 6,8 & 6,8 & 6,8 & 6,9 & 6,8 & 6,8 \\
\hline & nov/01 & 6,7 & 7,1 & 6,8 & 6,7 & 6,7 & 6,8 \\
\hline & jan/02 & 7,2 & 7,1 & 6,7 & 6,8 & 6,7 & 6,7 \\
\hline & $\mathrm{abr} / 02$ & 6,9 & 7,1 & 6,8 & 6,8 & 6,8 & 6,8 \\
\hline & jun/02 & 6,8 & 6,7 & 6,7 & 6,8 & 6,8 & 6,7 \\
\hline & jul/02 & 7,0 & 7,1 & 7,2 & 7,1 & 7,0 & 7,1 \\
\hline & ago/02 & 6,6 & 7,0 & 6,8 & 6,8 & 6,9 & 6,8 \\
\hline \multirow{7}{*}{ 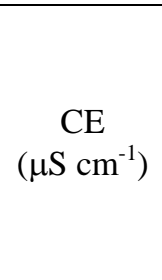 } & ago/01 & 1879 & 1671 & 1892 & 1704 & 1802 & 1921 \\
\hline & nov/01 & 2170 & 1950 & 2140 & 2060 & 2130 & 2180 \\
\hline & $\mathrm{jan} / 02$ & 1670 & 1460 & 1630 & 1460 & 1540 & 1680 \\
\hline & $\mathrm{abr} / 02$ & 2160 & 1910 & 2060 & 1910 & 2000 & 2610 \\
\hline & jun/02 & 2160 & 1800 & 2110 & 1800 & 1840 & 2370 \\
\hline & jul/02 & 2140 & 1820 & 2180 & 1780 & 2150 & 2400 \\
\hline & ago/02 & 2060 & 1799 & 2090 & 1785 & 1785 & 2220 \\
\hline \multirow{7}{*}{$\begin{array}{c}\mathrm{Cl}^{-} \\
\left(\mathrm{mg} \mathrm{L}^{-1}\right)\end{array}$} & ago/01 & 377,9 & 324,1 & 415,8 & 332,7 & 359,6 & 412,2 \\
\hline & nov/01 & 351,2 & 300,6 & 353,6 & 300,6 & 324,1 & 346,5 \\
\hline & jan/02 & 219,4 & 219,4 & 158,5 & 194,5 & 225,8 & 232,3 \\
\hline & $\mathrm{abr} / 02$ & 403,7 & 319.8 & 388,0 & 309,7 & 332,7 & 533,7 \\
\hline & jun/02 & 429,9 & 345,7 & 429,9 & 314,6 & 328,3 & 483,9 \\
\hline & jul/02 & 457,3 & 357,7 & 462,2 & 342,0 & 458,3 & 544,0 \\
\hline & ago/02 & 438,1 & 358,4 & 446,8 & 336,1 & 348,7 & 495,4 \\
\hline \multirow{7}{*}{$\begin{array}{c}\mathrm{K}^{+} \\
\left(\mathrm{mg} \mathrm{L}^{-1}\right)\end{array}$} & ago/01 & 0,3 & 0,2 & 0,3 & 0,3 & 0,3 & 0,3 \\
\hline & nov/01 & 0,6 & 0,5 & 0,6 & 0,6 & 0,7 & 0,6 \\
\hline & $\mathrm{jan} / 02$ & 1,9 & 2,4 & 2,4 & 2,8 & 2,6 & 2,1 \\
\hline & $\mathrm{abr} / 02$ & 4,0 & 2,7 & 3,7 & 3,7 & 3,3 & 4,3 \\
\hline & jun/02 & 3,3 & 3,0 & 3,3 & 3,3 & 3,3 & 3,6 \\
\hline & jul/02 & 3,0 & 2,7 & 3,3 & 3,3 & 3,0 & 3,6 \\
\hline & ago/02 & 3,4 & 2,8 & 3,4 & 3,4 & 3,4 & 3,4 \\
\hline
\end{tabular}


continuação

\begin{tabular}{c|c|c|c|c|c|c|c}
\hline \multirow{2}{*}{ Parâmetro } & \multirow{2}{*}{ Mês } & \multicolumn{6}{|c}{ POÇOS } \\
\cline { 3 - 8 } & & $\mathrm{P}-01 \mathrm{~A}$ & $\mathrm{P}-02 \mathrm{~A}$ & $\mathrm{P}-03 \mathrm{~A}$ & $\mathrm{P}-04 \mathrm{~A}$ & $\mathrm{P}-05 \mathrm{~A}$ & $\mathrm{P}-06 \mathrm{~A}$ \\
\hline \multirow{3}{*}{} & ago/01 & 155,3 & 131,30 & 147,3 & 144,6 & 160,6 & 152,6 \\
& nov/01 & 133,6 & 119,78 & 137,2 & 130,1 & 140,8 & 139,0 \\
$\mathrm{Na}^{+}$ & jan/02 & 73,2 & 68,23 & 65,4 & 101,4 & 114,3 & 80,5 \\
$\left(\mathrm{mg} \mathrm{L}^{-1}\right)$ & abr/02 & 133,1 & 111,18 & 126,0 & 124,6 & 133,1 & 143,3 \\
& jun/02 & 134,1 & 108,65 & 121,0 & 116,0 & 124,8 & 124,8 \\
& jul/02 & 151,8 & 127,52 & 137,0 & 139,4 & 144,3 & 154,4 \\
& ago/02 & 143,7 & 113,00 & 134,0 & 122,2 & 136,4 & 141,3 \\
\hline
\end{tabular}

A figura 4 apresenta os valores de CE, associados à pluviometria do município de Quixeré no período de agosto de 2001 a agosto de 2002. Em janeiro de 2002, mês de elevada pluviosidade, ocorreu uma redução na condutividade elétrica em todos os poços, indicando diluição dos sais no aqüífero pela recarga. Nos meses seguintes, de pluviosidade relativamente baixa, a condutividade elétrica voltou aos níveis de valores do período seco.
Neste período, à medida que as chuvas infiltraram no solo, carrearam o excedente de sais nele contidos, nas áreas agrícolas provavelmente proveniente de fertilizantes utilizados nos meses seguintes a janeiro, aumentando assim, a salinidade das águas. Os fertilizantes são aplicados, por gotejamento, duas vezes por semana durante todo o ano com dosagem de 1000 $\mathrm{kg} / \mathrm{ha}$ ano.
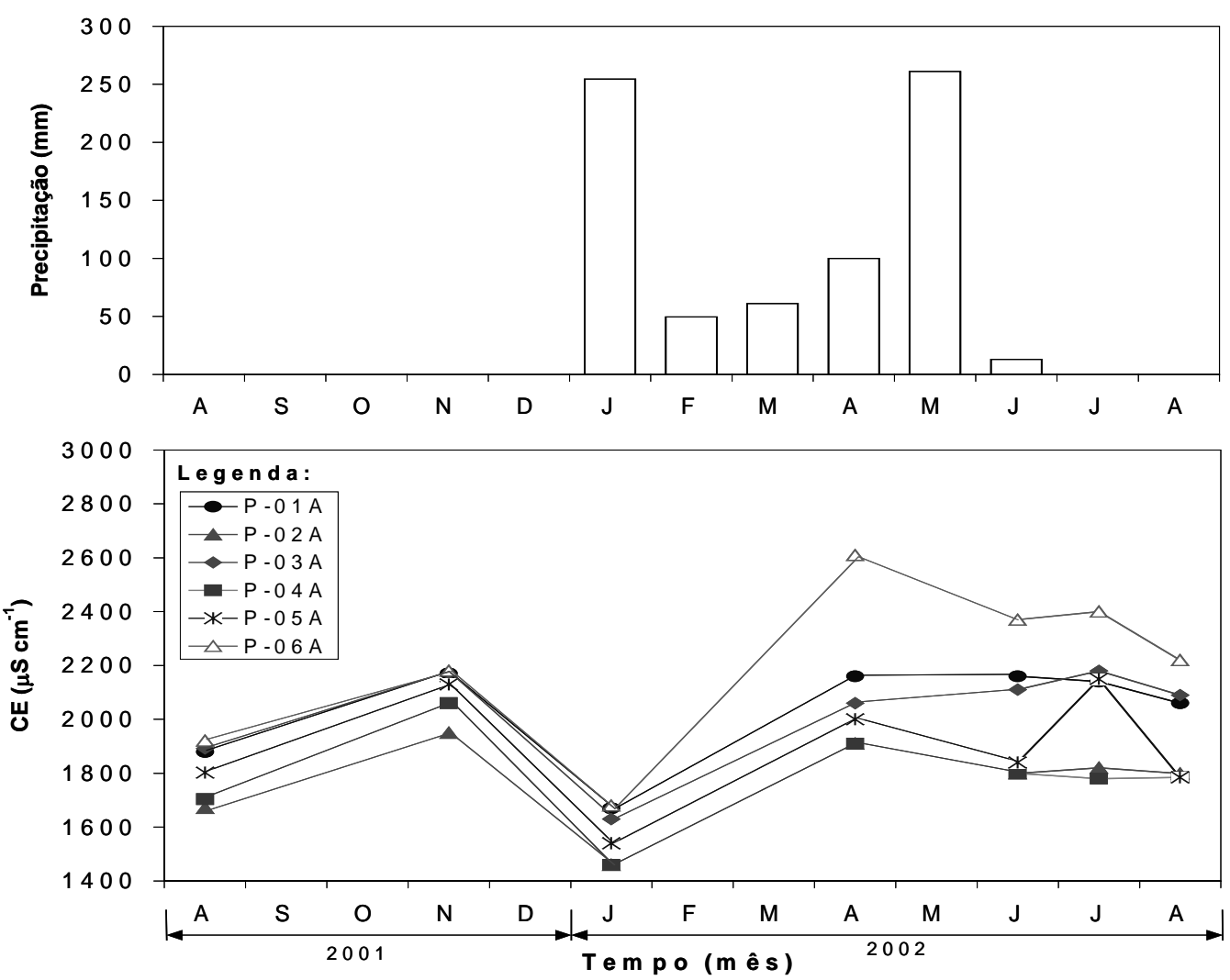

Figura 4 - Precipitação mensal e variação da condutividade elétrica na água dos poços.

Os valores de $\mathrm{pH}$ (Figura 5) nos poços P-03A a P-06A mantiveram-se em cerca de 6,7, no período de agosto/01 a junho/02. No poço P-01A, $\mathrm{o} \mathrm{pH}$ aumentou em janeiro/02 e diminuiu até junho/02, tendo, a partir daí, acompanhado o comportamento dos outros poços; no poço P-02A aumentou em novembro/01, atingindo aproximadamente 7,1 , até abril/02, diminuindo em junho/02 e mantendo, a partir daí, as características dos outros poços. De julho/02 para agosto/02, houve uma redução no $\mathrm{pH}$ de todos os poços. 

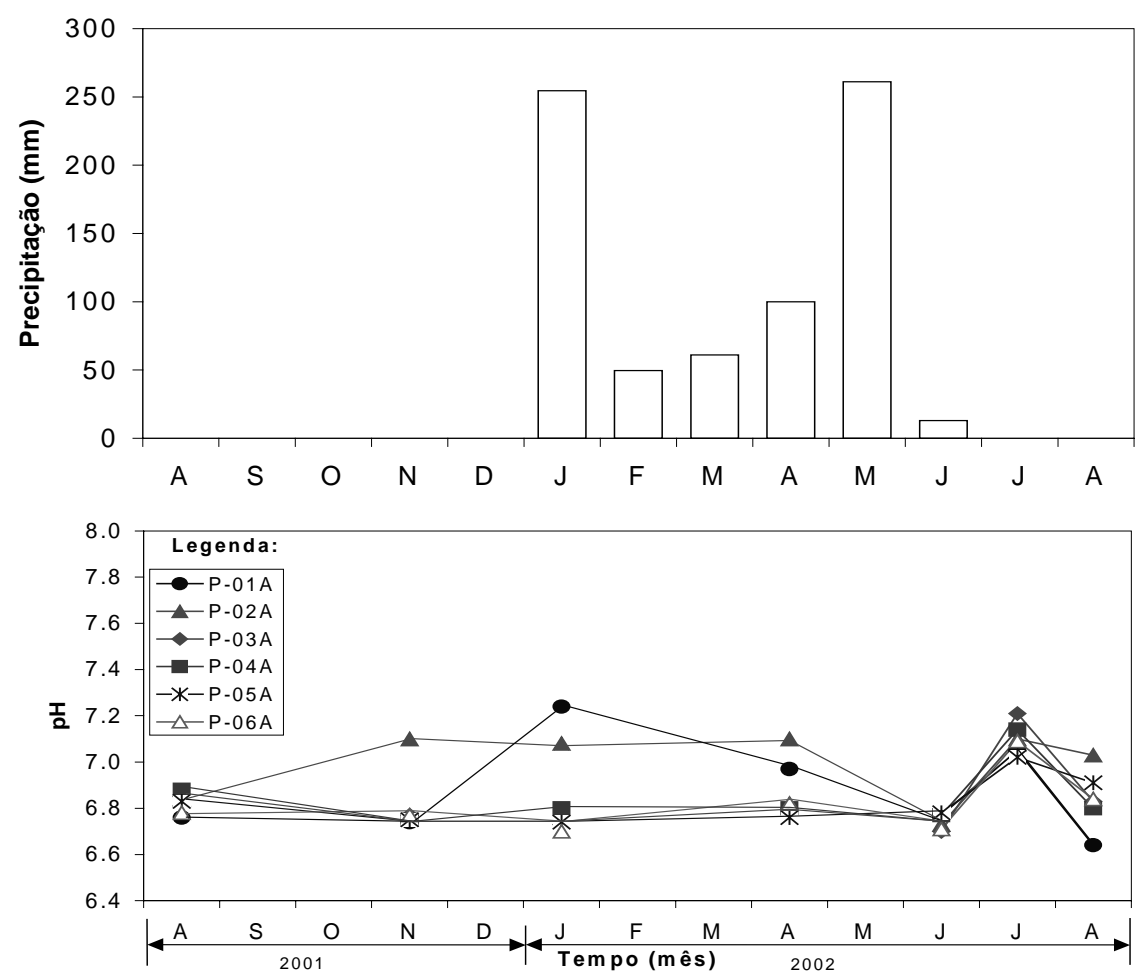

Figura 5 - Precipitação mensal e variação do pH.

A Figura 6 mostra um aumento progressivo nas concentrações do íon potássio a partir do início da estação chuvosa de janeiro/02, atingindo um máximo em abril/02 e estabilizando-se logo depois em torno de $3,3 \mathrm{mgL}^{-1}$. É importante observar que as concentrações estão com valores baixos em relação aos demais cátions.

$\mathrm{O}$ aumento no período chuvoso indica que $\mathrm{o}$ potássio é carreado de uma fonte externa para o aqüífero, através da recarga. Isto se deve à infiltração do fertilizante cloreto de potássio
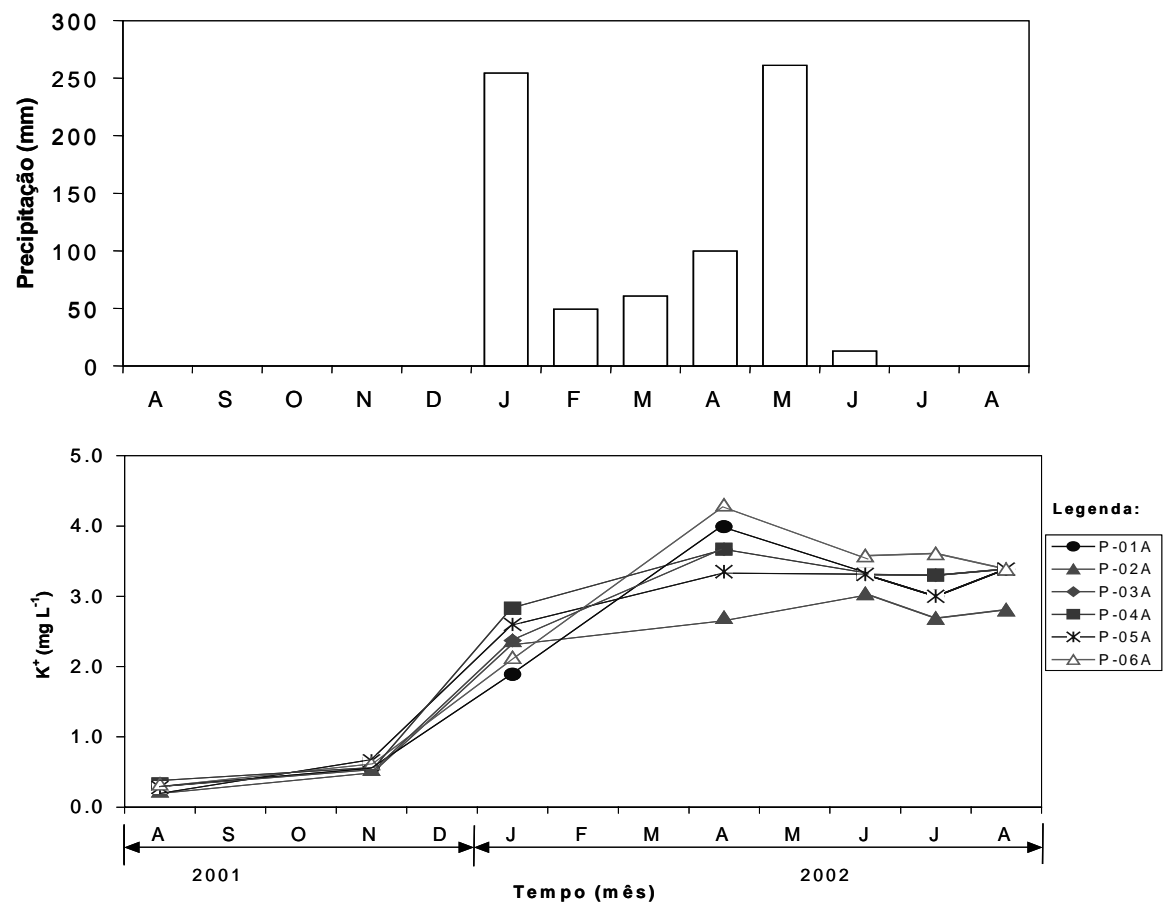

Figura 6 - Precipitação mensal e variação da concentração do íon potássio. 
A figura 7 mostra que a concentração do íon cloreto diminuiu com a recarga no mês de janeiro/02 e aumentou nos meses seguintes do período chuvoso, indicando o mesmo comportamento da CE (Figura 4) e a importância da contribuição dos cloretos para a salinização das águas do aqüífero.

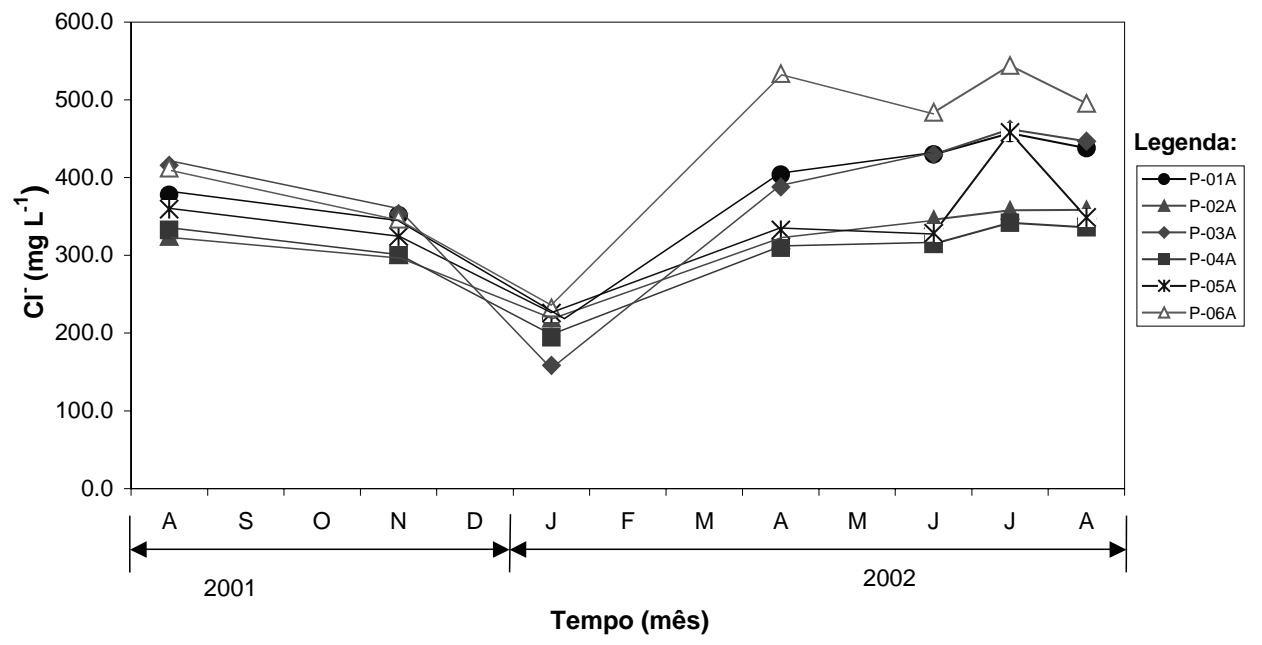

Figura 7 - Variação da concentração do íon cloreto no período de 13 meses.

A interferência do excesso de $\mathrm{KCl}$ na irrigação,no mês de abril/02 (Tabela 2). A qualidade das águas subterrâneas da Chapada do distribuição do íon cloreto na área pode ser Apodi é demonstrada através da comparação das visualizada através do mapa de isolinhas traçadas concentrações de cloretos obtidas em amostras pelo aplicativo "Surfer" (Figura 8). coletadas em poços dentro e fora do perímetro de

Tabela 2 - Localização dos pontos amostrados e concentrações de cloretos e sódio em águas subterrâneas de áreas agrícolas e não agrícolas na Chapada do Apodi, em abril de 2002.

\begin{tabular}{|c|c|c|c|c|c|c|}
\hline & POÇOS & $\mathrm{CO}$ & $\begin{array}{l}\text { NADAS } \\
\text { M) }\end{array}$ & CONC & IÇÃO & CE \\
\hline & & Latitude Sul & Longitude Oeste & $\mathrm{Cl}^{-}$ & $\mathrm{Na}^{+}$ & \\
\hline & P01 & 621.4034 & 9417.3298 & 75,9 & 47,0 & 920 \\
\hline & P02 & 621.2890 & 9416.9872 & 164,6 & 80,0 & 1200 \\
\hline & P03 & 621.9751 & 9417.5582 & 126,3 & 88,0 & 1300 \\
\hline .0 & P04 & 616.4175 & 9420.6189 & 236,6 & 106,0 & 1500 \\
\hline$\Xi$ & P05 & 607.6422 & 9430.1753 & 59,1 & 38,0 & 684 \\
\hline iृg & P06 & 606.2928 & 9430.1296 & 197,3 & 69,0 & 1550 \\
\hline$\pi$ & P07 & 613.7945 & 9435.2527 & 229,1 & 82,0 & 1419 \\
\hline 宗 & P08 & 616.8521 & 9419.7738 & 145,0 & 85,0 & 1460 \\
\hline & P09 & 619.7634 & 9432.8087 & 377,7 & 114,0 & 1984 \\
\hline & P10 & 626.0529 & 9437.9251 & 377,7 & 100,0 & 1919 \\
\hline & P11 & 622.8967 & 9436.3262 & 186,1 & 84,0 & 1271 \\
\hline & P12 & 609.0454 & 9423.4512 & 95,5 & 59,0 & 624.0 \\
\hline & P13 & 609.4571 & 9422.2406 & 364,6 & 113,0 & 1860.0 \\
\hline & $\mathrm{P}-01 \mathrm{~A}$ & 626.5750 & 9438.2170 & 403,7 & 133,1 & 2160.0 \\
\hline$\frac{\pi}{\pi}$ & P-02A & 626.5100 & 9438.8480 & 319,8 & 111,2 & 1910.0 \\
\hline 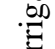 & P-03A & 625.3230 & 9438.2870 & 388,0 & 126,0 & 2060.0 \\
\hline 光 & P-04A & 626.2350 & 9439.3240 & 309,7 & 124,6 & 1910.0 \\
\hline 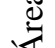 & P-05A & 625.3400 & 9438.2170 & 332,7 & 133,1 & 2000.0 \\
\hline & P-06A & 625.3050 & 9438.6250 & 535,7 & 143,3 & 2610.0 \\
\hline
\end{tabular}



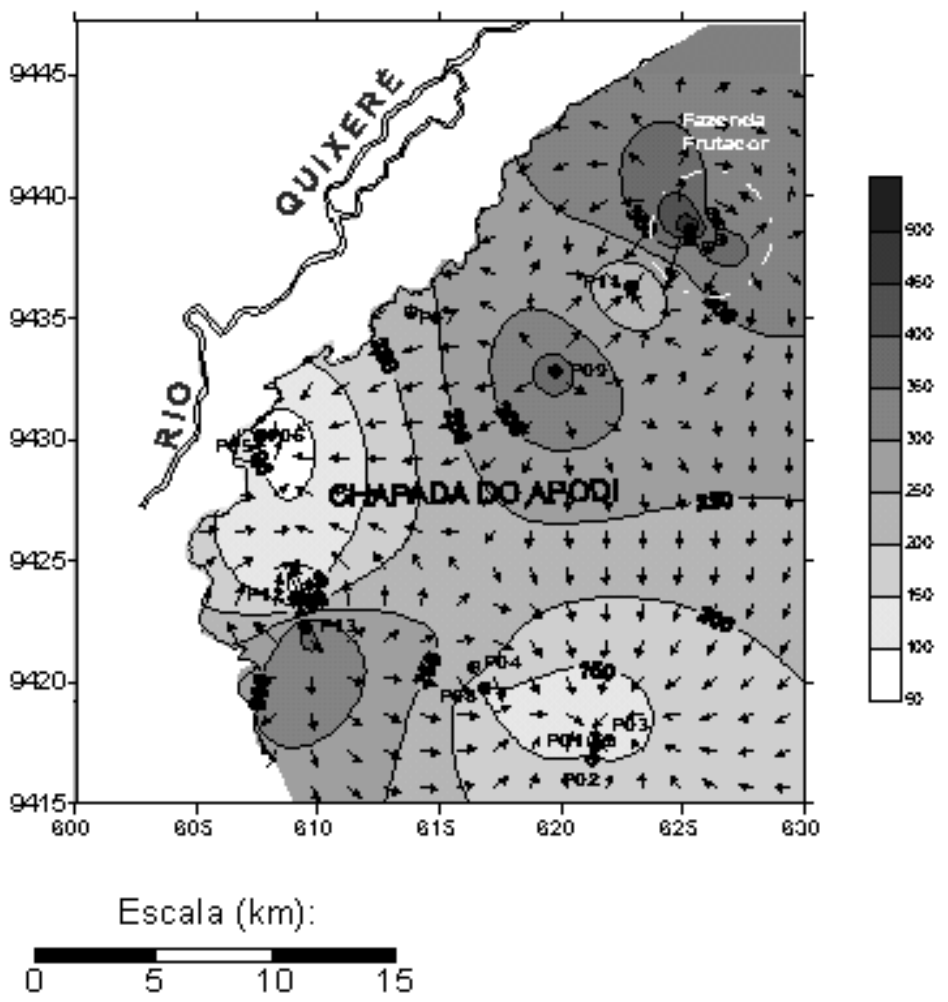

Figura 8 - Distribuição de cloretos em águas subterrâneas da chapada do Apodi com locação dos poços.

A Figura 9 mostra o gráfico $\mathrm{rCl}^{-}$vs. $\mathrm{rNa}^{+}$, marinha, proveniente dos sedimentos marinhos ou para a área agrícola e fora dela de uma da deposição de aerossóis marinhos. As águas amostragem realizada no mês de abril/02. Pode-se coletadas na área agrícola e na sua observar que as concentrações mais baixas de $\mathrm{Cl}^{-}$circunvizinhança apresentam aumento de 4 para (em 20\% das amostras), para áreas não agrícolas e $15 \mathrm{meq}^{-1} \mathrm{em} \mathrm{rCl}^{-}$com $\mathrm{rNa}^{+}$no patamar de, distantes das agrícolas, se enquadram na reta $\mathrm{rNa}^{+}$aproximadamente, $4 \mathrm{meq} \mathrm{L}^{-1}$, significando que $\mathrm{Cl}^{-}$ $=\mathrm{rCl}^{-}$indicando a dissolução da halita de origem aumenta sem ser ligado ao $\mathrm{Na}^{+}$.

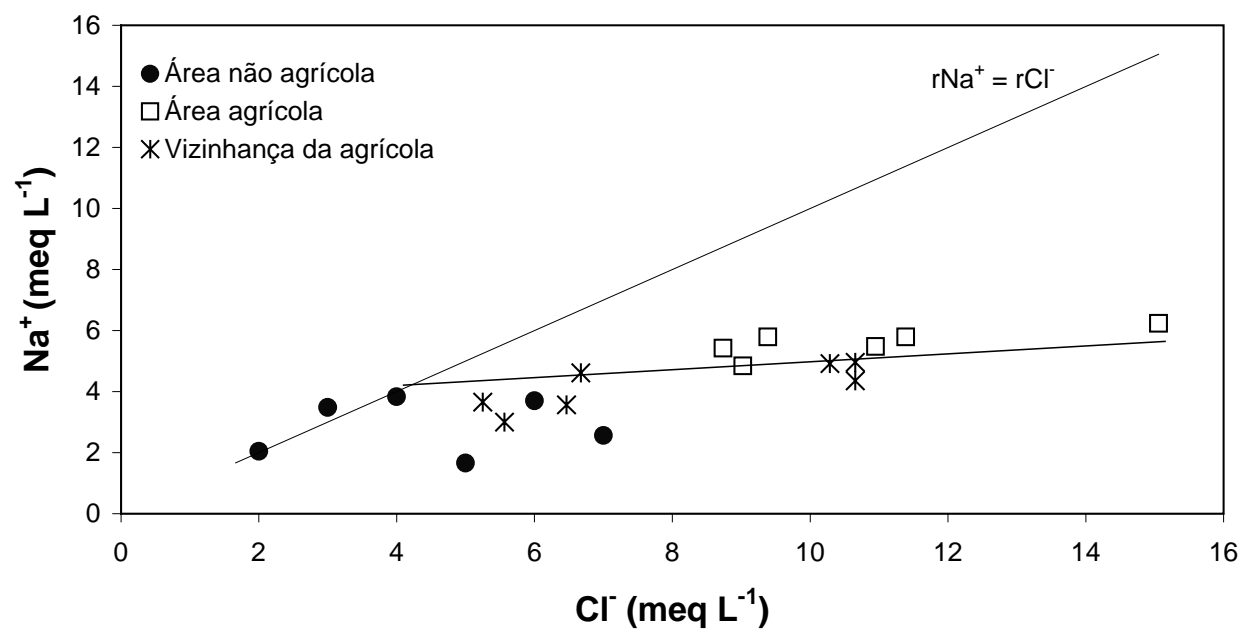

Figura $9-\mathrm{rCl}^{-}$vs. $\mathrm{rNa}^{+}$em águas de poços em áreas agrícolas e não agrícolas na Chapada do Apodi, em abril de 2002.

A percentagem do cloreto, em relação aos sulfatos e bicarbonatos variou com o tempo nos seis poços como mostra a figura 10. De agosto/01 a novembro/01, período seco, o percentual de cloreto permaneceu com valores na faixa de $53 \%$ a $59 \%$ em todos os poços. No mês de janeiro/02, 
com a infiltração das chuvas no aqüífero, ocorreu uma diminuição somente no poço P-03A. Os poços P-02A, P-04A e P-05A apresentaram o mesmo comportamento durante todo o período, e o poço P-06A apresentou o maior aumento percentual de $\mathrm{Cl}^{-}$.

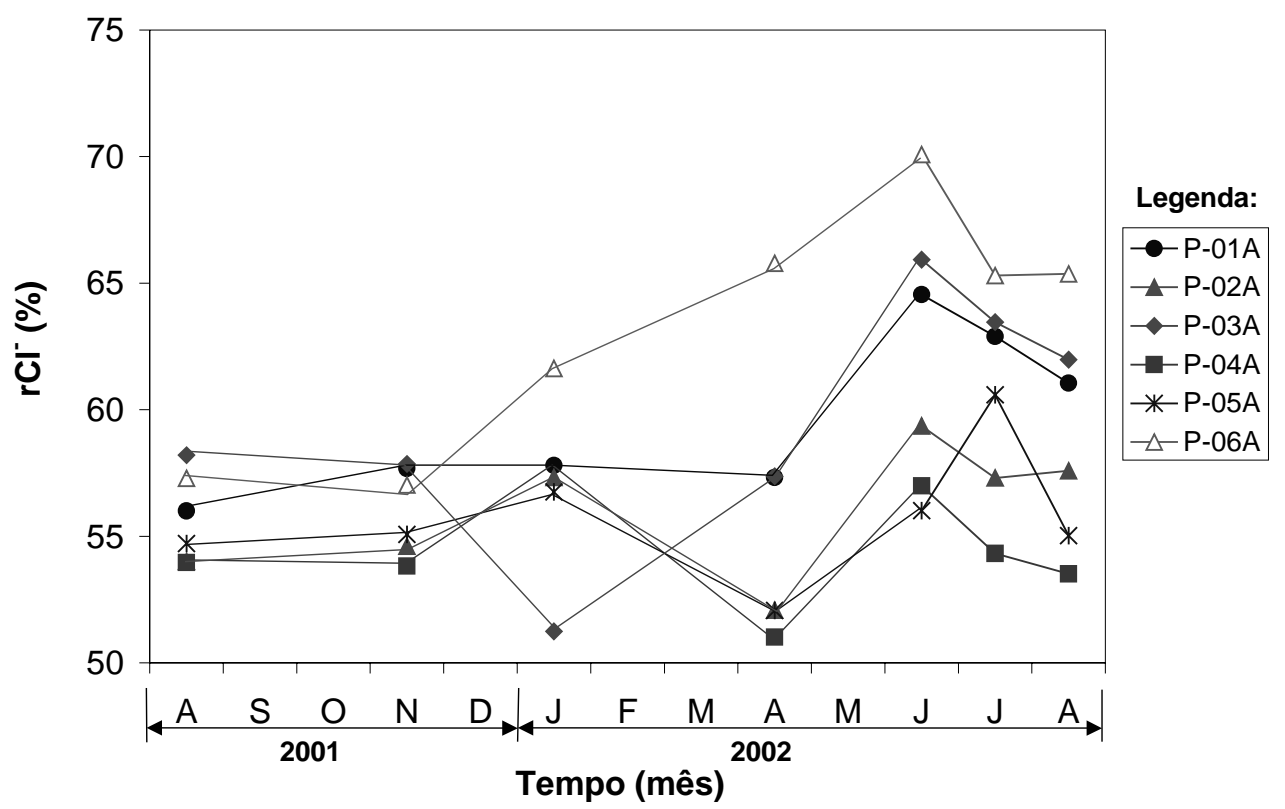

Figura 10 - Variação do percentual do íon cloreto com relação ao tempo nas águas da área agrícola no período de um ano.

É importante observar que no final do período de um ano, o $\mathrm{rCl}(\%)$, na faixa de $54 \%$ a $66 \%$, foi maior do que no início, na maioria dos poços, o que é um indicativo de que o $\mathrm{KCl}$ usado como fertilizante está deixando resíduo de cloreto na água.

\section{Medidas Isotópicas}

As análises de oxigênio-18 (Tabela 3) foram feitas em todas as amostras da área agrícola, em três meses distintos do ciclo hidrológico, mostram valores de $\delta^{18} \mathrm{O}$ que são notavelmente uniformes com interconexão entre os pontos de amostragem, sugerindo a existência de um aqüífero (diferente de áreas cristalinas com estocagem de água em fraturas isoladas)
O valor de $\delta^{18} \mathrm{O}$ médio de $-2,28 \%$, menos negativo que o valor médio das chuvas na área, que é em torno de -3,20\%o (SANTIAGO et al., 2001), indica que as águas sofreram evaporação antes da recarga. A Figura 11 mostra os valores de $\delta^{18} \mathrm{O}$ das três coletas comparados com o $\delta^{18} \mathrm{O}$ médio das chuvas na área.

Porém, de acordo com medidas de Santiago (1984), que relacionou evaporação e $\delta^{18} \mathrm{O}$ (o enriquecimento em ${ }^{18} \mathrm{O}$ ) a evaporação é menor que $10 \%$, não podendo ser responsável por aumentos significativos da salinidade das águas.

Tabela 3 - Valores de $\delta^{18} \mathrm{O}$ das águas subterrâneas da Formação Jandaíra na Chapada do Apodi.

\begin{tabular}{c|c|l|l|l|l|l|l}
\hline \multirow{2}{*}{ Parâmetro } & Mês & \multicolumn{7}{|c}{ POÇOS } \\
\cline { 3 - 8 } & & P-01A & P-02A & P-03A & P-04A & P-05A & P-06A \\
\hline \multirow{3}{*}{$\delta^{18} \mathrm{O}$} & Ago/01 & $-2,59$ & $-2,53$ & $-2,44$ & -2.43 & $-2,41$ & $-2,45$ \\
$(\% / 00)$ & Nov/01 & $-2,56$ & $-2,23$ & $-2,02$ & $-2,32$ & $-2,30$ & $-2,27$ \\
\cline { 3 - 8 } & Jun/02 & $-2,59$ & $-2,47$ & $-2,40$ & $-2,43$ & $-2,33$ & $-2,12$ \\
\hline
\end{tabular}




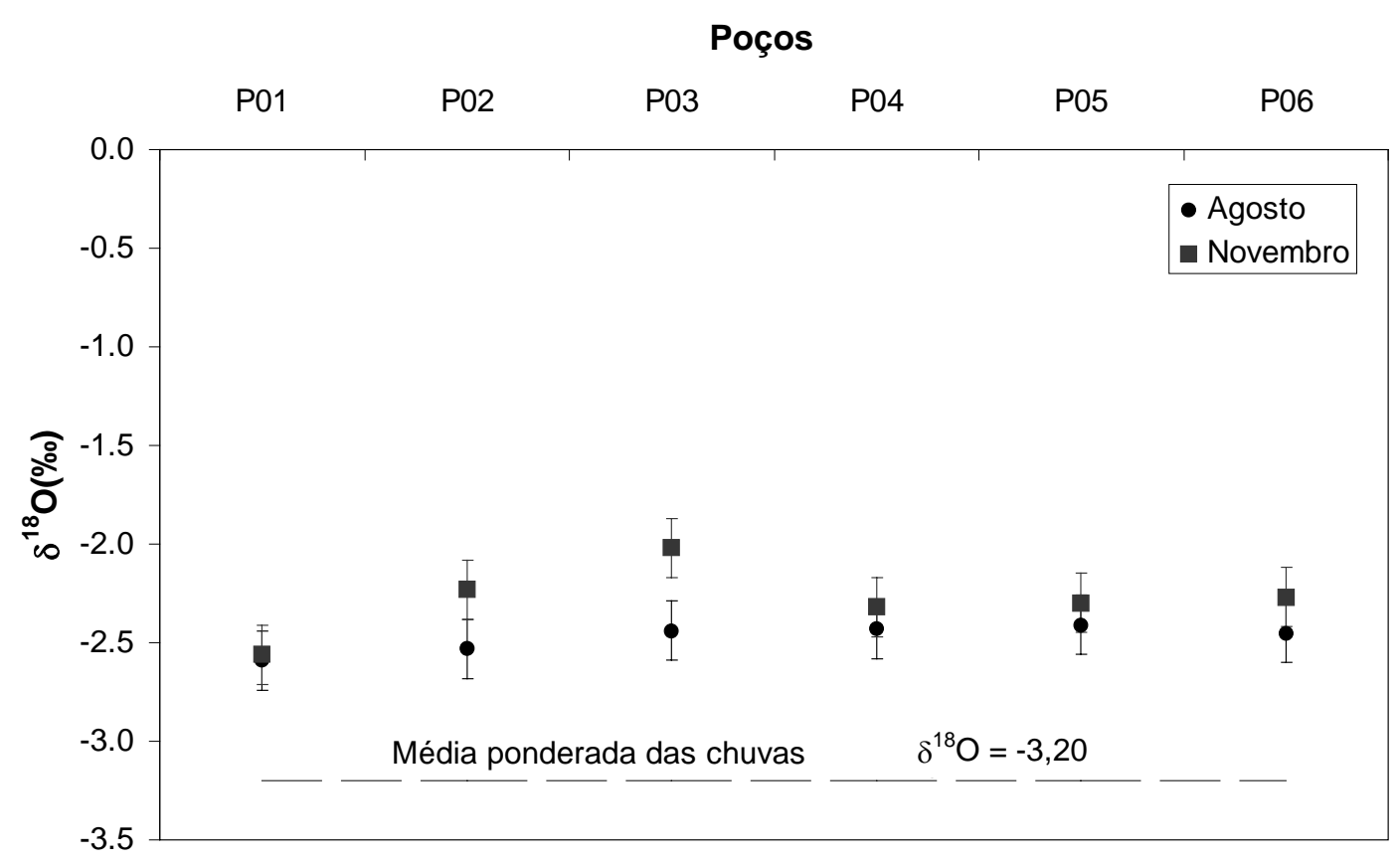

Figura $12-\delta^{18} \mathrm{O}$ em águas subterrâneas na Chapada do Apodi em três diferentes coletas.

\section{CONCLUSÕES}

O íon potássio, proveniente do $\mathrm{KCl}$, utilizado como fertilizante na agricultura da Chapada, é facilmente assimilado pelo sistema solo - planta, enquanto o íon cloreto, que é conservativo, é carreado para o aqüífero, tornando-se fonte de salinização das águas. $\mathrm{O}$ aumento neste íon,observado no período de estudo, é muito provavelmente, decorrente do que não foi assimilado, ou seja, foi colocado em excesso.

Suspeita-se, que na Chapada do Apodi, a utilização do $\mathrm{KCl}$ na atividade agrícola tem elevado a concentração salina. No entanto, o sistema volta a níveis próximos ao do estado natural. É necessário um monitoramento contínuo da qualidade da água subterrânea da Chapada para evitar prejuízos a este recurso.

Desta forma, com um sistema racional de aplicação de fertilizantes, associado a um monitoramento contínuo das águas do aqüífero, é possível manter condições que permitam que o sistema mantenha a salinização natural.

\section{AGRADECIMENTOS}

À CAPES, à FUNCAP (Fundação Cearense de Apoio ao Desenvolvimento Científico e Tecnológico) pelo apoio financeiro e à UNIVALE (nas pessoas de Dr. João Teixeira Júnior e José Aldair) pelo apoio logístico e aos amigos Luiz Alberto e Roberval.

\section{REFERÊNCIAS}

APHA. Standard Methods For the examination of water and wastewater. 18 ed., AWWA - WPCP, 1992.

CRAIG, H. Standard for reporting concentrations of deuterium and oxygen-18 in natural waters. Science, 1833-4, 1961.

FEITOSA, E. C. A explotação do aqüífero Açu na região de Mossoró - RN: Caracterização da situação atual e perspectiva de atendimento da demanda futura (Programa de água subterrânea para a região nordeste - Série Hidrogeologia: Pesquisa e Desenvolvimento, 1). Brasília: CPRM, 1996. 44p, 1996.
SANTIAGO, M. M. F. Mecanismos de Salinização em região semi-árida. Estudo de açudes Pereira de Miranda e Caxitoré no Ceará. São Paulo, 1984. Tese (Doutorado em.Geociências). Instituto de Geociências - USP. SANTIAGO, M. F.; FRISCHKORN, H.; SALES NETO, P.; MENDES FILHO, J.; The recharge mechanisms in an alluvial aquifer zone in northeast Brazil. Ground water, v. 39, n. 1, p. $18-23,2001$. 